\title{
The first records of Spirometra erinaceieuropaei (Cestoda: Diphyllobothriidae), a causative agent of human sparganosis, in Latvian wildlife
}

\author{
Guna Bagrade ${ }^{1}$ (1) - Ivica Králová-Hromadová ${ }^{2}$ (D) Eva Bazsalovicsová ${ }^{2}$ (1) $\cdot$

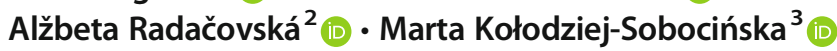

Received: 20 April 2020 / Accepted: 1 November 2020 / Published online: 10 November 2020

(C) The Author(s) 2020

\begin{abstract}
Diphyllobothriid tapeworms of the genus Spirometra are causative agents of sparganosis, food-borne zoonotic parasitic disease. They have been recorded in broad spectrum of hosts, including humans, in all continents except Antarctica. Spirometra tapeworms have been intensively studied in several Asian countries; however, they have been rather neglected in Europe. The aim of this study was to provide a pilot screening of Spirometra spp. in Latvia, where data on sparganosis are not available. Tapeworms morphologically identified as diphyllobothriid species were isolated from grey wolves Canis lupus and Eurasian lynxes Lynx lynx from Latvia during the hunting periods 2013-2019. The parasites were subjected to molecular genotyping using sequences of the partial large (LSU rDNA; $615 \mathrm{bp}$ ) and small (SSU rDNA; $720 \mathrm{bp}$ ) subunits of the nuclear ribosomal RNA gene and complete (1566 bp) cytochrome $c$ oxidase subunit I gene of the mitochondrial DNA (cox1 mtDNA). Analyses of both ribosomal subunits of 13 tapeworms revealed no intraspecific variation within the respective rDNA subunits. On the other hand, sequence analysis of mitochondrial cox 1 revealed intraspecific polymorphism displayed by 12 cox 1 haplotypes. Comparison of the current data with sequences of the corresponding DNA regions deposited in the GenBank revealed 99.3-99.5\% (LSU rDNA), 99.2\% (SSU rDNA) and 99.6-100\% (cox1 mtDNA) identity of studied tapeworms with Spirometra erinaceieuropaei, which provided the first confirmation of this diphyllobothriid tapeworm in Latvia. Since S. erinaceieuropaei is probably prevalent in Latvian wildlife and may also occur in other potential host species, further studies are needed in order to acquire complex data on its geographic distribution and transmission in the natural environment of Latvia, as well as on the spectrum of its intermediate, paratenic, and definitive hosts.
\end{abstract}

Keywords Lynxlynx $\cdot$ Canislupus $\cdot$ Parasitic zoonosis $\cdot$ Definitivehost $\cdot$ Moleculargenotyping $\cdot$ RibosomalDNA $\cdot$ Mitochondrial DNA

\section{Introduction}

Sparganosis is a food-borne zoonosis caused by larval stages (plerocercoids) of diphyllobothriid tapeworms of the genus

Section Editor: Hiroshi Sato

Marta Kołodziej-Sobocińska

mksobocinska@ibs.bialowieza.pl

1 Latvian State Forest Research Institute "Silava", Rigas 111, Salaspils LV-2169, Latvia

2 Institute of Parasitology, Slovak Academy of Sciences, Hlinkova 3, 04001 Kosice, Slovakia

3 Mammal Research Institute, Polish Academy of Sciences, Stoczek 1, 17-230 Białowieża, Poland
Spirometra (Liu et al. 2015). They have been recorded in humans, domesticated and wild animals in all continents except Antarctica (Scholz et al. 2019). Although several species have been recognized in the genus, the taxonomy of Spirometra tapeworms is not fully resolved and requires further clarification (Kuchta et al. 2020). Currently, Spirometra erinaceieuropaei (Rudolphi 1819) is the species most often identified in natural environments in Europe (Kondzior et al. 2018; Kołodziej-Sobocińska et al. 2019; Scholz et al. 2019; Kuchta et al. 2020); however, recent data also reported the first confirmation of $S$. mansoni in amphibians in Romania (Kuchta et al. 2020).

The life cycle of $S$. erinaceieuropaei involves copepods (Cyclops sp.) as the first intermediate hosts, in which the first stage larva (procercoid) develops. Various vertebrate species 
of amphibians, reptiles, birds, and mammals may serve as the second intermediate (or paratenic) hosts. In these types of hosts, the second stage larva (plerocercoid), named spargana, develops mainly in subcutaneous tissues and/or muscles (Kuchta et al. 2015). In Europe, almost 40 species of vertebrates were reported as intermediate hosts (e.g. pool frog Pelophylax lessonae, marsh frog Pelophylax ridibundus, grass snake Natrix natrix, common viper Vipera berus) (Shimalov 2009; Kondzior et al. 2018; Kuchta et al. 2020) and paratenic hosts (e.g. European badger Meles meles, European mink Mustela lutreola, American mink Neovison vison, European polecat Mustela putorius) (Shimalov and Shimalov 2002a; Anisimova 2004; Kołodziej-Sobocińska et al. 2014, 2019; Kuchta et al. 2020). Canids and felids, such as grey wolf Canis lupus, Eurasian Lynx lynx lynx, wild cat Felis silvestris, and cat Felis catus, are exclusively definitive hosts (Furmaga 1953; Shimalov and Shimalov 2000; Craig and Craig 2005; Kołodziej-Sobocińska et al. 2018; Kuchta et al. 2020), while raccoon dog Nyctereutes procyonoides or red fox Vulpes vulpes have been recognized as both definitive and paratenic hosts (Furmaga 1953; Shimalov and Shimalov 2002b, 2003; Kuchta et al. 2020).

While most human cases have been reported from Asia, e.g. China, South Korea, and Thailand (Wiwanitkit 2005; Liu et al. 2015; Hong et al. 2016; Wang et al. 2018), some reports have also been published from Europe, e.g. Italy, Poland, France, Czech Republic, and Germany (Pampiglione et al. 2003; Czyżewska et al. 2019). Humans can be infected either by drinking water contaminated with infected copepods, or by ingestion of plerocercoids present in raw or undercooked meat of second intermediate or paratenic hosts. Adult Spirometra tapeworms are also able to mature in the human intestine and can cause a rare disease called spirometrosis, which usually does not result in clinical symptoms (Le et al. 2017). However, the most serious and lifethreatening form is proliferative sparganosis (Kikuchi and Maruyama 2020). In Asia, the majority of human cases were most probably connected with the consumption of amphibians and reptiles (Wiwanitkit 2005; Liu et al. 2015), which are not considered to be a source of infection in Europe due to different eating habits. However, wild boar Sus scrofa meat cannot be ruled out as a source of infection in Europe (KołodziejSobocińska et al. 2016; Czyżewska et al. 2019), since it has been recorded as a paratenic host of $S$. erinaceieuropaei in Serbia, Belarus, Ukraine, and recently in Poland (Rukavina et al. 1957; Shimalov 2009; Nevolko and Litvinenko 2014; Kołodziej-Sobocińska et al. 2016).

Knowledge about the geographic distribution of S. erinaceieuropaei in Europe has been scarce. Since 2000, the tapeworm has been recorded in various wildlife species in Belarus (Shimalov and Shimalov 2000, 2002a, b, 2003; Anisimova 2004; Shimalov 2009), Serbia (Nevolko and Litvinenko 2014), Ukraine (Kornyushin et al. 2011), and most recently in Poland, where $S$. erinaceieuropaei was confirmed by molecular analyses for the first time in Europe (KołodziejSobocińska et al. 2014, 2016, 2018, 2019; Kondzior et al. 2018). It is highly probable that $S$. erinaceieuropaei is also present in other European countries but has been overlooked due to a number of factors. Firstly, some of the hosts are protected species, which can be subjected to detailed parasitological examination only under strict conditions and special permissions. Secondly, the specific location of plerocercoid larvae in subcutaneous tissues and/or muscles of intermediate or paratenic hosts means that the presence of this parasite may be overlooked during standard dissection and parasitological examination, if specific methodology focusing on detection of spargana is not utilized. Finally, taxonomic identification of larval Spirometra stages, including $S$. erinaceieuropaei, is complicated owing to the absence of reliable species-specific morphological markers (Kuchta et al. 2015, 2020). Although identification of adult tapeworms based on morphological features is possible (Scioscia et al. 2014), DNA-based genotyping is often recommended in order to confirm the results (Badri et al. 2017; Kołodziej-Sobocińska et al. 2018; Kuchta et al. 2020). The aim of the present work was to acquire additional data on the occurrence of $S$. erinaceieuropaei in Europe, with particular focus on Latvia, where a pilot screening of this zoonotic tapeworm in definitive hosts was performed by molecular genotyping.

\section{Materials and methods}

The material in the current work originated from the helminthological collection at the Latvian State Forest Research Institute "Silava" in Salaspils, Latvia. In the 2013-2019 hunting seasons, grey wolves (July-March) and Eurasian lynxes (December-March) were hunted within the national legal framework according to the quota allocated by the Latvian Hunting Regulations. A total of 35 hosts, 11 Eurasian lynxes and 24 grey wolves of different ages (juveniles and adults) and sexes (males and females) were examined (Table 1). Figure 1 provides scheme of geographic location of examined Eurasian lynxes and grey wolves in Latvia; all hosts except for one originated from the eastern part of the country.

After complete helminthological dissection, all helminths were taxonomically identified using morphological criteria, preserved in $70 \%$ ethanol and deposited in the helminthological collection of the above mentioned institution. For the current work, 44 adult tapeworms were selected from the helminthological collection and subjected to molecular genotyping. The tapeworms were isolated from intestines of Eurasian lynxes and grey wolves immediately after dissection, and they were identified as "diphyllobothriid tapeworms." Taxonomical identification of diphyllobothriideans is difficult and requires properly fixed and processed material for an 
accurate morphological description which should be supplemented with molecular genotyping. Since the condition of tapeworms isolated from Eurasian lynxes and grey wolves did not allow reliable morphological description, the material was fixed in ethanol for further identification by molecular genotyping.
Genomic DNA was isolated from $20 \mathrm{mg}$ of tissue of 44 diphyllobothriidean tapeworms using the QIAamp® DNA Kit (QIAGEN, Hilden, Germany) following the manufacturer's instructions, diluted in deionized water and stored at $20{ }^{\circ} \mathrm{C}$. Molecular genotyping was performed by Polymerase Chain Reaction (PCR) amplification of a partial fragment of

Table 1 Details of hosts and GenBank accession numbers of ribosomal and mitochondrial genes of Spirometra erinaceieuropaei from Latvia

\begin{tabular}{|c|c|c|c|c|c|c|c|c|c|c|}
\hline $\mathrm{No}^{\mathrm{a}}$ & Code & Age & Gender & Season & Locality & $\mathrm{No}^{\mathrm{c}}$ & LSU rDNA & SSU rDNA & $\operatorname{cox} 1 \mathrm{mtDNA}$ & $\operatorname{cox} 1$ haplotype \\
\hline 1 & L1 & A & $\mathrm{F}$ & 2013-2014 & Barkava & 2 & - & - & - & - \\
\hline 2 & $\mathrm{~L} 2^{\mathrm{b}}$ & n.a. & M & 2014-2015 & Atašiene & 1 & - & - & - & - \\
\hline 3 & L3 & n.a. & M & 2014-2015 & Mālpils & 1 & MT313931 & MT313809 & MT941770 & CO1-Ha2/LV \\
\hline 4 & $\mathrm{~L} 4$ & A & $\mathrm{F}$ & 2015-2016 & Goliševa & 1 & - & - & - & - \\
\hline 5 & L5 & A & $\mathrm{F}$ & 2015-2016 & Kārķi & 1 & - & - & - & - \\
\hline 6 & L6 & A & $\mathrm{F}$ & 2015-2016 & Nītaure & 1 & MT637917 & MT637928 & MT941769 & CO1-Ha1/LV \\
\hline 7 & L7 & n.a. & M & 2016-2017 & Dundaga & 1 & - & - & - & - \\
\hline 8 & L8 & n.a. & M & 2016-2017 & Jaunanna & 1 & - & - & - & - \\
\hline 9 & L9 & A & $\mathrm{F}$ & 2016-2017 & Madliena & 1 & - & - & - & - \\
\hline 10 & L10 & A & M & 2017-2018 & Cesvaine & 1 & MT637915 & MT637921 & MT941768 & CO1-Ha3/LV \\
\hline 11 & L11 & $\mathrm{J}$ & $\mathrm{F}$ & 2018-2019 & Variņi & 2 & - & - & - & - \\
\hline 12 & W1 & n.a. & M & 2013-2014 & Jērcēnu & 2 & - & - & - & - \\
\hline 13 & W2 & $\mathrm{J}$ & M & 2013-2014 & Litene & 1 & MT321262 & MT321261 & MT951150 & CO1-Ha4/LV \\
\hline 14 & W3 & $\mathrm{J}$ & M & 2014-2015 & Litene & 3 & - & - & - & - \\
\hline 15 & W4 & n.a. & $\mathrm{F}$ & 2014-2015 & Salacgrīva & 3 & - & - & - & - \\
\hline 16 & W5 & $\mathrm{A}$ & M & 2014-2015 & Umurga & 1 & MT637916 & MT637929 & MT951146 & CO1-Ha5/LV \\
\hline 17 & W6 & n.a. & M & 2014-2015 & Lubāna & 1 & MT637923 & MT637924 & MT951155 & CO1-Ha6/LV \\
\hline 18 & W7 & $\mathrm{J}$ & M & 2014-2015 & Salacgrīva & 1 & - & - & - & - \\
\hline 19 & W8 & $\mathrm{J}$ & M & 2015-2016 & Vestiena & 1 & MT637918 & MT634698 & MT951154 & CO1-Ha7/LV \\
\hline 20 & W9 & $\mathrm{J}$ & M & 2015-2016 & Elkšņi & 1 & - & - & - & - \\
\hline 21 & W10 & A & $\mathrm{F}$ & 2015-2016 & Galēni & 2 & - & - & - & - \\
\hline 22 & W11 & $\mathrm{J}$ & $\mathrm{F}$ & 2015-2016 & Malnava & 1 & - & - & - & - \\
\hline 23 & W12 & $\mathrm{J}$ & $\mathrm{F}$ & 2015-2016 & Salnava & 1 & MT637926 & MT637933 & MT951153 & CO1-Ha8/LV \\
\hline 24 & W13 & $\mathrm{J}$ & M & 2015-2016 & Liezēre & 1 & MT637920 & MT637934 & MT951147 & CO1-Ha9/LV \\
\hline 25 & W14 & n.a. & M & 2015-2016 & Ainaži & 1 & - & - & - & - \\
\hline 26 & W15 & n.a. & $\mathrm{F}$ & 2015-2016 & Vestiena & 1 & - & - & - & - \\
\hline 27 & W16 & n.a. & $\mathrm{F}$ & 2015-2016 & Atašiene & 1 & MT637925 & MT637935 & MT951148 & CO1-Ha10/LV \\
\hline 28 & W17 & A & $\mathrm{F}$ & 2015-2016 & Mežāre & 1 & - & - & - & - \\
\hline 29 & W18 & A & $\mathrm{F}$ & 2015-2016 & Mežāre & 1 & - & - & - & - \\
\hline 30 & W19 & $\mathrm{J}$ & M & 2016-2017 & Mazzalve & 1 & MT637919 & MT637930 & MT951152 & CO1-Ha1/LV \\
\hline 31 & W20 & A & $\mathrm{F}$ & 2016-2017 & Umurga & 2 & - & - & - & - \\
\hline 32 & W21 & n.a. & $\mathrm{F}$ & 2017-2018 & Skulte & 1 & MT637927 & MT637932 & MT951149 & CO1-Ha11/LV \\
\hline 33 & W22 & $\mathrm{A}$ & $\mathrm{F}$ & 2017-2018 & Klintaine & 1 & MT637922 & MT637931 & MT951151 & CO1-Ha12/LV \\
\hline 34 & W23 & A & M & 2017-2018 & Murmastiene & 1 & - & - & - & - \\
\hline 35 & W24 & $\mathrm{A}$ & $\mathrm{F}$ & 2017-2018 & Murmastiene & 1 & - & - & - & - \\
\hline
\end{tabular}

Individuals molecularly confirmed as Spirometra erinaceieuropaei are in italics

$L$ Eurasian lynx, $W$ grey wolf, $A$ adult, $J$ juvenile, $F$ female, $M$ male, $n$.a. data not available, - data not obtained

${ }^{\text {a }}$ Number of host

${ }^{\mathrm{b}}$ Roadkill

${ }^{\mathrm{c}}$ Number of tapeworms 
the nuclear large subunit of the ribosomal RNA gene (LSU rDNA) and a partial fragment of the nuclear small subunit of the ribosomal RNA gene (SSU rDNA). LSU rDNA was amplified using the LSU-5 (5'-TAGGTCGACCCGCT GAAYTTAAGCA-3') and $1500 \mathrm{R}$ (5'-GCTA TCCTGAGGGAAACTTCG-3') primers originally described by Olson et al. (2003). Universal primers WormA (5'-GCGA ATGGCTCATTAAATCAG-3') and WormB (5'-CTTG TTACGACTTTTACTTCC-3') (Littlewood and Olson 2001) were used for amplification of SSU rDNA. In addition, the complete cytochrome $c$ oxidase subunit I of the mitochondrial DNA (cox1 mtDNA) was amplified using the Diphyllo-Cox1F (5'-TAGACTAAGTGTTTTCAAAACACTA-3') and Diphyllo-Cox1-R (5'-ATAGCATGATGCAAAAGG-3') primers described by Yanagida et al. (2010).

The PCR amplification conditions were $5 \mathrm{~min}$ at $94{ }^{\circ} \mathrm{C}$ as an initial step, then 30 cycles of $1 \mathrm{~min}$ at $94^{\circ} \mathrm{C}, 1 \mathrm{~min}$ at $55^{\circ} \mathrm{C}$, $2 \mathrm{~min}$ at $72{ }^{\circ} \mathrm{C}$, and finally $10 \mathrm{~min}$ at $72^{\circ} \mathrm{C}$. The PCR products were visualized on a $1.5 \%$ agarose gel and purified using exonuclease I and shrimp alkaline phosphatase (Werle et al. 1994). Sequencing was performed by the automatic genetic analyser Applied Biosystems 3130xl (Applied Biosystems, Foster City, California, USA) and the BigDye Terminator v3.1 Cycle sequencing kit (Applied Biosystems). Sequencing of LSU rDNA, SSU rDNA, and cox 1 mtDNA was performed from both directions using following PCR primers and internal primers. The 5 'end of LSU rDNA amplification product was sequenced with LSU-5 primer (primer used for PCR amplification) and two internal primers, 300F (5'-CAAGTACCGTGAGGGAAAGTTG-3') and 400R (5'GCAGCTTGACTACACCCG-3') (Olson et al. 2003). Similarly, the 5'end of SSU rDNA was sequenced with PCR primer WormA and two internal primers 600F (5'-GGTG CCAGCAGCCGCG-3') and 600R (5'- ACCGCGGC TGCTGGCACC-3') (Littlewood and Olson 2001). The complete sequence of $\operatorname{cox} 1 \mathrm{mtDNA}$ was obtained with two PCR amplification primers Diphyllo-Cox1-F and Diphyllo-Cox1$\mathrm{R}$ (Yanagida et al. 2010) and two internal primers, DCox1-R2 (5'-AAACACCGGCTCACGTAAAG-3') and Cox1-R3 (5'CGCAAATGCCGAATAAAGAG-3') (KołodziejSobocińska et al. 2019). Contiguous sequences were assembled and inspected for errors using the Geneious software

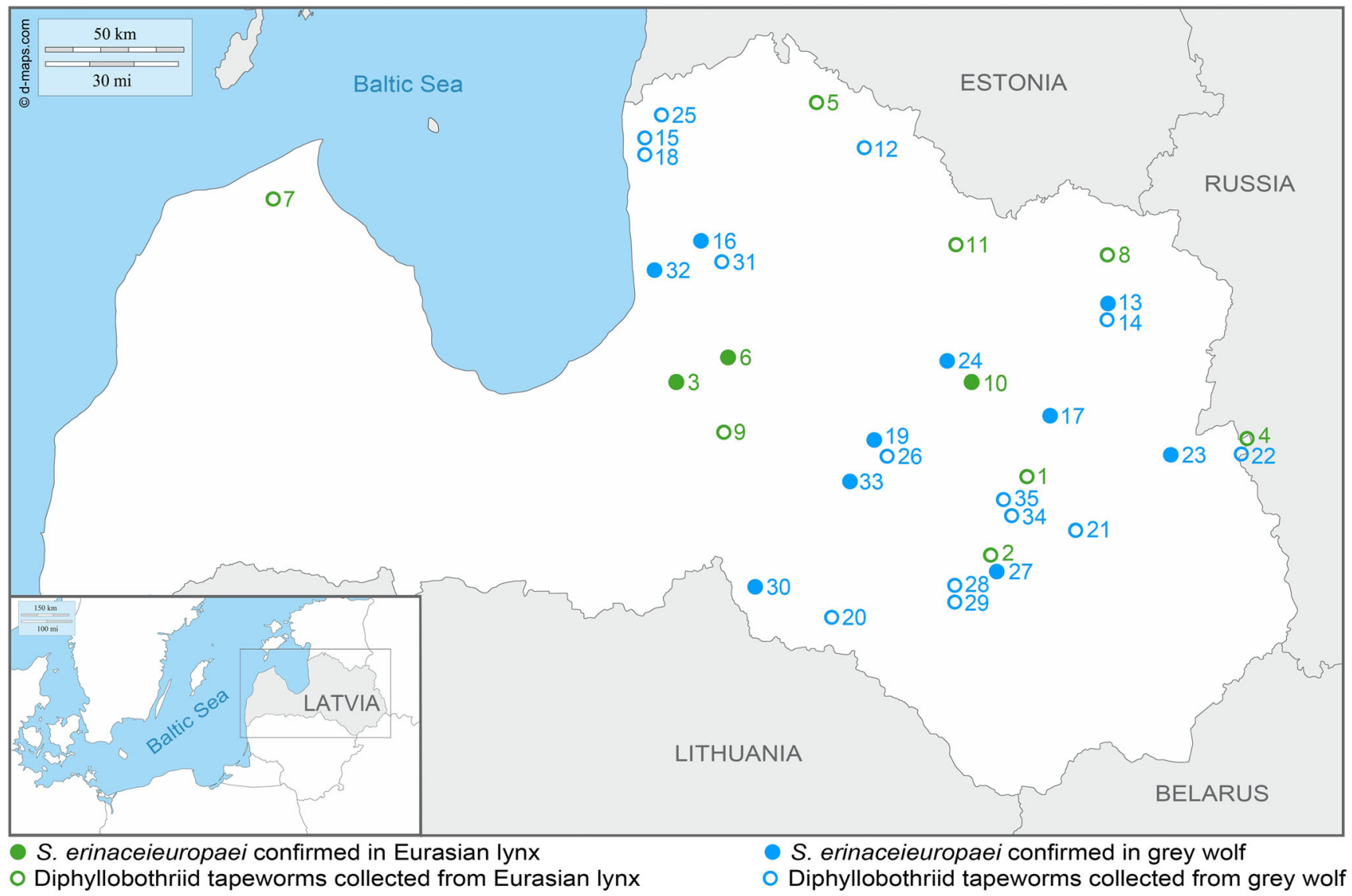

Fig. 1 Map of collection sites of diphyllobothriid tapeworms isolated from Eurasian lynxes (green circle) and grey wolves (blue circle) in Latvia with specification of hosts in which Spirometra erinaceieuropaei was molecularly confirmed (full circles). Details of individual hosts are

provided in Table 1; the numbering of hosts follows the numbers indicated in the column "number of host." The map was created using Photoshop CS4, version 11.0 
(version 10.0.5, Biomatters, Auckland, New Zealand). Obtained sequences were compared with sequences deposited in GenBank using nucleotide BLAST search.

\section{Results and discussion}

Of the 44 diphyllobothriid tapeworms analysed in the current work, PCR products of partial LSU rDNA, partial SSU rDNA and complete $\operatorname{cox} 1$ were successfully amplified in 13 specimens. PCR amplifications of both ribosomal subunits and mitochondrial $\operatorname{cox} 1$ were repeatedly carried out under different reaction conditions; however, 31 samples did not yield any amplicons. A possible explanation may be that hunted animals are often provided to the parasitological laboratories at an advanced level of decomposition of the content of their gastro-intestinal tracts. A prolonged period between animal necropsy and parasite fixation may consequently result in a lower level of effectiveness of molecular analyses due to DNA degradation.

Sequence analyses of $615 \mathrm{bp} \mathrm{LSU}$ rDNA and $720 \mathrm{bp}$ SSU rDNA of 13 tapeworms revealed identical sequence structure within the respective ribosomal subunit with no intraspecific variation. Comparison of the obtained LSU rDNA sequences with sequences deposited in GenBank revealed 99.5\% pairwise sequence identity with LSU rDNA of $S$. erinaceieuropaei (GenBank accession number KY552835) isolated from dog Canis familiaris from Australia and $99.3 \%$ with S. erinaceieuropaei (KY552836) from yellow-spotted keelback snake Xenochrophis flavipunctatus from Vietnam (Waeschenbach et al. 2017). Similarly, comparison of the $720 \mathrm{bp}$ fragment of partial SSU rDNA with sequences deposited in GenBank revealed 99.2\% identity with respective SSU rDNA region of S. erinaceieuropaei (KY552801) isolated from dog from Australia (Waeschenbach et al. 2017).

Sequence analyses of complete mitochondrial cox 1 sequences (1566 bp) of 13 studied tapeworms revealed intraspecific variation displayed by $1-4$ substitutions corresponding to the overall 99.5-99.9\% sequence identity. While two individuals (L6 and W19) possessed identical cox1 sequence assigned as CO1-Ha1/LV (cox 1 haplotype no. 1 from Latvia), each of the remaining 11 specimens were characterized by a unique $\operatorname{cox} 1$ structure corresponding to the specific haplotype CO1-Ha2/LV-CO1-Ha12/LV (Table 1). Comparison of the currently obtained cox 1 haplotypes from Latvia with complete cox 1 sequences deposited in the GenBank revealed the highest level of sequence identity (99.7-100\%) with S. erinaceieuropaei from Poland (MT131826) and Finland (99.6-99.9\%; MT131825 (Kuchta et al. 2020).

Sequences of LSU rDNA, SSU rDNA and $\operatorname{cox} 1$ of all 13 individuals were deposited in GenBank, EMBL and DDBJ databases under accession numbers summarized in Table 1. To conclude, all 13 diphyllobothriidean tapeworms obtained from three Eurasian lynxes and ten grey wolves were molecularly identified as $S$. erinaceieuropaei, providing the first record of this species in Latvia.

Carnivores are important definitive hosts of a wide range of protozoan and metazoan parasites and can play a significant role in the maintenance of different zoonoses (Craig and Craig 2005; Han et al. 2016). Eurasian lynx and grey wolf populations are distributed throughout the entire territory of Latvia. Both populations have increased since the beginning of the 2000s and numbers are estimated within 400-600 for Eurasian lynx and 300-500 for grey wolf (Ozoliņš et al. 2017a, b).

Helminth fauna of Eurasian lynxes from Latvia has been mainly represented by nematodes (Trichinella britovi, Trichinella nativa, Toxocara mystax, Eucoleus aerophilus (syn. Thominx aerophilus) and Pearsonema feliscati (syn. Capilaria felis-cati)) and a single tapeworm (Taenia pisiformis) and trematode (Alaria alata) (Bagrade et al. 2003; Deksne et al. 2016; Ozolina et al. 2019). A broader spectrum of helminths has been detected in grey wolves from Latvia. In particular, a single trematode (Alaria alata) and several nematodes (Ancylostoma caninum, Crenosoma vulpis, Eucoleus aerophilus, Pearsonema plica, T. britovi, Toxocara canis, and Uncinaria stenocephala) were recorded after parasitological examination of grey wolves hunted throughout the country (Bagrade et al. 2009; Deksne et al. 2016). In addition, cyclophyllidean tapeworms represented by Echinococcus granulosus, Echinococcus multilocularis, Mesocestoides lineatus, and several Taenia species (T. crassiceps, T. hydatigena, T. krabbei, T. multiceps, T. pisiformis, and T. polyacantha) were found in grey wolves from Latvia. Dibothriocephalus latus (syn. Diphyllobothrium latum) was detected in a single grey wolf from Latvia as the only representative of diphyllobothriidean tapeworms (Bagrade et al. 2009). However, the taxonomic identification of all mentioned helminths reported from grey wolves and Eurasian lynxes from Latvia was based only on their morphology and no molecular genotyping was performed.

Since taxonomic identification of diphyllobothriidean tapeworms based only on morphology is difficult (Kuchta et al. $2015,2020)$ and the previously published occurrence of D. latus in a grey wolf in Latvia (Bagrade et al. 2009) was not confirmed by molecular methods, further studies focused on detailed morphological descriptions supplemented with molecular genotyping of diphyllobothriids are highly recommended for their more accurate taxonomic identification in Latvian wildlife. Dibothriocephalus latus is evidently circulating in the natural environment in Latvia because its larval stages, plerocercoids, were detected during ichthyoparasitological examinations in several fish species (Kirjušina and Vismanis 2007). In addition, human cases of diphyllobothriosis (up to 10 cases 
over 2010-2014) have been recorded in patients from Latvia by the Centre for Disease Prevention and Control (https://spkc. gov.lv). However, it is evident that more data on the occurrence, prevalence, geographic distribution, and a spectrum of intermediate and definitive hosts of D. latus in Latvia are required for the up-to-date knowledge on circulation of this most frequent causative agent of diphyllobothriosis in Europe.

It is not possible to conclude if our findings represent a recent introduction of $S$. erinaceieuropaei to Latvia, or if this tapeworm has been present in the Latvian environment for a prolonged period. Since sparganosis has been confirmed in neighbouring Belarus (Shimalov and Shimalov 2000, 2002a, b, 2003; Shimalov 2009) and geographically proximal Poland (Kołodziej-Sobocińska et al. 2014, 2016, 2018, 2019) and Finland (Lavikainen et al. 2013; Kuchta et al. 2020), it seems highly probable that $S$. erinaceieuropaei had been present in Latvia for a longer time.

The current study provided initial data on spirometrosis in Latvia, but reveals several perspectives for future studies. Investigating the role of particular intermediate and paratenic hosts of S. erinaceieuropaei is highly important for understanding its life cycle and dispersal in the natural environment in Latvia. In addition, the potential zoonotic risk of human sparganosis connected with wild boar meat consumption or drinking contaminated water should be examined from a medical health perspective.

Authors' contributions All authors contributed to the study conception and design. Guna Bagrade provided helminthological dissection of hosts, collection of parasitic material and its initial morphological identification. Molecular analyses were performed by Ivica Králová-Hromadová, Eva Bazsalovicsová, and Alžbeta Radačovská. Marta Kołodziej-Sobocińska, Ivica Králová-Hromadová, and Eva Bazsalovicsová wrote the first draft of manuscript; all authors read and approved the final manuscript. Guna Bagrade and Eva Bazsalovicsová prepared Table 1 and Alžbeta Radačovská draw Fig. 1.

Funding Open access funding provided by Mammal Research Institute PAS. The work was financially supported by the Slovak Research and Development Agency under contract APVV-15-0004 and Slovak Grant Agency VEGA no. 2/0134/17 and Fund for Hunting Development of the Ministry of Agriculture (Latvia).

\section{Compliance with ethical standards}

Conflict of interest The authors declare that they have no conflict of interest.

Open Access This article is licensed under a Creative Commons Attribution 4.0 International License, which permits use, sharing, adaptation, distribution and reproduction in any medium or format, as long as you give appropriate credit to the original author(s) and the source, provide a link to the Creative Commons licence, and indicate if changes were made. The images or other third party material in this article are included in the article's Creative Commons licence, unless indicated otherwise in a credit line to the material. If material is not included in the article's Creative Commons licence and your intended use is not permitted by statutory regulation or exceeds the permitted use, you will need to obtain permission directly from the copyright holder. To view a copy of this licence, visit http://creativecommons.org/licenses/by/4.0/.

\section{References}

Anisimova EI (2004) Study on the European mink Mustela lutreola helminthocenoses in connection with the American mink M. vison expansion in Belarus: story of the study and review of the results. Helminthologia 41:193-196

Badri M, Eslahi AV, Majidiani H, Pirestani M (2017) Spirometra erinaceieuropaei in a wildcat (Felis silvestris) in Iran. Vet Parasitol Reg Stud Reports 10:58-61. https://doi.org/10.1016/j. vprsr.2017.08.004

Bagrade G, Vismanis K, Kirjušina M, Ozolinšs J (2003) Preliminary results on the helminthofauna of the Eurasian lynx (Lynx lynx) in Latvia. Acta Zool Lituan 13:3-7. https://doi.org/10.1080/ 13921657.2003.10512536

Bagrade G, Kirjušina M, Vismanis K, Ozoliṇš (2009) Helminth parasites of the wolf Canis lupus from Latvia. J Helminthol 83:63-68. https:// doi.org/10.1017/s0022149x08123860

Craig HL, Craig PS (2005) Helminth parasites of wolves (Canis lupus): a species list and an analysis of published prevalence studies in Nearctic and Palaearctic populations. J Helminthol 79:95-103. https://doi.org/10.1079/joh2005282

Czyżewska J, Namiot A, Koziołkiewicz K, Matowicka-Karna J, Dzięcioł J, Kemona H (2019) The first case of human sparganosis in Poland and a review of the cases in Europe. Parasitol Int 70:89-91. https:// doi.org/10.1016/j.parint.2019.02.005

Deksne G, Seglina Z, Jahundovica I, Esite Z, Bakasejevs E, Bagrade G, Keidane D, Interisano M, Marucci G, Tonanzi D, Pozio E, Kirjusina M (2016) High prevalence of Trichinella spp. in sylvatic carnivore mammals of Latvia. Vet Parasitol 231:118-123. https://doi.org/10. 1016/j.vetpar.2016.04.012

Furmaga S (1953) Spirometra janickii sp. n. (Diphyllobothriidae). Acta Parasitol Pol 1:29-59

Han BA, Kramer AM, Drake JM (2016) Global patterns of zoonotic disease in mammals. Trends Parasitol 32:565-577. https://doi.org/ 10.1016/j.pt.2016.04.007

Hong Q, Feng J, Liu H, Li X, Gong L, Yang Z, Yang W, Liang X, Zheng R, Cui Z, Wang W, Chen D (2016) Prevalence of Spirometra mansoni in dogs, cats, and frogs and its medical relevance in Guangzhou, China. Int J Infect Dis 53:41-45. https://doi.org/10. 1016/j.ijid.2016.10.013

Kikuchi T, Maruyama H (2020) Human proliferative sparganosis update. Parasitol Int 75:102036. https://doi.org/10.1016/j.parint.2019. 102036

Kirjušina M, Vismanis K (2007). Checklist of the parasites of fishes of Latvia. Food and Agriculture Organization of the United Nations. FAO fisheries technical paper 369/3. Rome 2007. http://www.fao. org/3/a1078e/a1078e.pdf

Kołodziej-Sobocińska M, Tokarska M, Kowalczyk R (2014) The first report of sparganosis (Spirometra sp.) in Eurasian badger (Meles meles). Parasitol Int 63:397-399. https://doi.org/10.1016/j.parint. 2013.12.011

Kołodziej-Sobocińska M, Miniuk M, Ruczyńska I, Tokarska M (2016) Sparganosis in wild boar (Sus scrofa) - implications for veterinarians, hunters, and consumers. Vet Parasitol 227:115-117. https:// doi.org/10.1016/j.vetpar.2016.08.001

Kołodziej-Sobocińska M, Yakovlev Y, Schmidt K, Hurníková Z, Ruczyńska I, Bednarski M, Tokarska M (2018) Update of the 
helminth fauna in Eurasian lynx (Lynx lynx) in Poland. Parasitol Res 117:2613-2621. https://doi.org/10.1007/s00436-018-5953-0

Kołodziej-Sobocińska M, Stojak J, Kondzior E, Ruczyńska I, Wójcik JM (2019) Genetic diversity of two mitochondrial DNA genes in Spirometra erinaceieuropaei (Cestoda: Diphyllobothriidae) from Poland. J Zool Syst Evol Res 57:764-777. https://doi.org/10.1111/ jzs. 12319

Kondzior E, Tokarska M, Kowalczyk R, Ruczyńska I, Sobociński W, Kołodziej-Sobocińska M (2018) The first case of genetically confirmed sparganosis (Spirometra erinaceieuropaei) in European reptiles. Parasitol Res 117:3659-3662. https://doi.org/10.1007/s00436018-6079-0

Kornyushin V, Malyshko EI, Malega AM (2011) The helminths of wild predatory mammals of Ukraine. Cestodes. Vest Zool 45:1-8

Kuchta R, Scholz T, Brabec J, Narduzzi-Wicht B (2015) Diphyllobothrium, Diplogonoporus and Spirometra. In: Xiao L, Ryan U, Feng Y (eds) Biology of foodborne parasites. CRC Press, Boca Raton, pp 299-326

Kuchta R, Kołodziej-Sobocińska M, Brabec J, Młocicki D, Sałamatin R, Scholz T (2020) Sparganosis (Spirometra) in Europe in the molecular era. Clin Infect Dis https://doi.org/10.1093/cid/ciaa1036/ 5875650

Lavikainen A, Haukisalmi V, Deksne G, Holmala K, Lejeune M, Isomursu M, Jokelainen P, Nareaho A, Laakkonen J, Hoberg EP, Sukura A (2013) Molecular identification of Taenia spp. in the Eurasian lynx (Lynx lynx) from Finland. Parasitology 140:653662. https://doi.org/10.1017/s0031182012002120

Le AT, Do LQT, Nguyen HBT, Nguyen HNT, Do AN (2017) Case report: the first case of human infection by adult of Spirometra erinaceieuropaei in Vietnam. BMC Infect Dis 17:669. https://doi. org/10.1186/s12879-017-2786-x

Littlewood DTJ, Olson PD (2001) Small subunit rDNA and the Platyhelminthes: signal, noise, conflict and compromise. In: Littlewood DTJ, Bray RA (eds) Interrelationships of the Platyhelminthes. Taylor and Francis, London, pp 262-278

Liu Q, Li MW, Wang ZD, Zhao GH, Zhu XQ (2015) Human sparganosis, a neglected food borne zoonosis. Lancet Infect Dis 15:1226-1235. https://doi.org/10.1016/s1473-3099(15)00133-4

Nevolko OM, Litvinenko OP (2014) Sparganosis in wild pigs. Vet Med 99:150-153

Olson PD, Cribb TH, Tkach VV, Bray RA, Littlewood DTJ (2003) Phylogeny and classification of the Digenea (Platyhelminthes: Trematoda). Int J Parasitol 33:733-755. https://doi.org/10.1016/ s0020-7519(03)00049-3

Ozolina Z, Bagrade G, Deksne G (2019) First confirmed case of Alaria alata mesocercaria in Eurasian lynx (Lynx lynx) hunted in Latvia. Parasitol Res 119:759-762. https://doi.org/10.1007/s00436-01906556-8

Ozoliņš J, Bagrade G, Ornicāns A, Žunna A, Done G, Stepanova A, Pilāte D, Šuba J, Lūkins M, Howlett SJ (2017a) Action plan for Eurasian lynx Lynx lynx conservation and management. LSFRI Silava. https://www.daba.gov.lv/upload/File/DOC_SAP/AP eurasian_lynx_18_EN.pdf. Accessed 13 March 2020

Ozoliņš J, Žunna A, Ornicāns A, Done G, Stepanova A, Pilāte D, Šuba J, Lūkins M, Howlett SJ, Bagrade G (2017b) Action plan for grey wolf
Canis lupus conservation and management. LSFRI Silava. https:// www.daba.gov.lv/upload/File/DOC_SAP/AP_grey_wolf_17_EN. pdf. Accessed 13 March 2020

Pampiglione S, Fioravanti ML, Rivasi F (2003) Human sparganosis in Italy - case report and review of the European cases. Apmis 111: 349-354. https://doi.org/10.1034/j.1600-0463.2003.1110208.x

Rukavina J, Džumurov N, Delič S (1957) Larvae of Diphyllobothrium erinacei europaei in pigs. Veterinaria 6:46-55

Scholz T, Kuchta R, Brabec J (2019) Broad tapeworms (Diphyllobothriidae), parasites of wildlife and humans: recent progress and future challenges. Int J Parasitol-Parasit Wildl 9:359-369. https://doi.org/10.1016/j.ijppaw.2019.02.001

Scioscia NP, Petrigh RS, Beldomenico PM, Denegri GM (2014) The Pampas fox (Lycalopex gymnocercus) as new definitive host for Spirometra erinacei (Cestoda: Diphyllobothriidae). Acta Trop 133:78-82. https://doi.org/10.1016/j.actatropica.2014.02.006

Shimalov VV (2009) Spirometrosis and sparganosis and other diphyllobothriases in the Republic of Belarus and their medical significance. Med Parazitol 3:48-52

Shimalov VV, Shimalov VT (2000) Helminth fauna of the wolf (Canis lupus Linnaeus, 1758) in Belorussian Polesie. Parasitol Res 86:163164. https://doi.org/10.1007/s004360050026

Shimalov VV, Shimalov VT (2002a) Helminth fauna of the European polecat (Mustela putorius Linnaeus, 1758) in Belorussian Polesie. Parasitol Res 88:259-260. https://doi.org/10.1007/s00436-0010521-3

Shimalov VV, Shimalov VT (2002b) Helminth fauna of the racoon dog (Nyctereutes procyonoides Gray, 1834) in Belorussian Polesie. Parasitol Res 88:944-945. https://doi.org/10.1007/s00436-0010582-3

Shimalov VV, Shimalov VT (2003) Helminth fauna of the red fox (Vulpes vulpes Linnaeus, 1758) in southern Belarus. Parasitol Res 89:77-78. https://doi.org/10.1007/s00436-002-0701-9

Waeschenbach A, Brabec J, Scholz T, Littlewood DTJ, Kuchta R (2017) The catholic taste of broad tapeworms - multiple routes to human infection. Int J Parasitol 47:831-843. https://doi.org/10.1016/j. ijpara.2017.06.004

Wang FM, Li WY, Gong SP, Wei YF, Ge Y, Yang GD, Xiao JJ (2018) Spirometra erinaceieuropaei severely infect frogs and snakes from food markets in Guangdong, China: implications a highly risk for zoonotic sparganosis. Trop Biomed 35:408-412

Werle E, Schneider C, Renner M, Volker M, Fiehn W (1994) Convenient single step, one tube purification of PCR products for direct sequencing. Nucleic Acids Res 22:4354-4355

Wiwanitkit V (2005) A review of human sparganosis in Thailand. Int J Infect Dis 9:312-316. https://doi.org/10.1016/j.ijid.2004.08.003

Yanagida T, Matsuoka H, Kanai T, Nakao M, Ito A (2010) Anomalous segmentation of Diphyllobothrium nihonkaiense. Parasitol Int 59: 268-270. https://doi.org/10.1016/j.parint.2009.12.006

Publisher's note Springer Nature remains neutral with regard to jurisdictional claims in published maps and institutional affiliations. 